Article

\title{
Handling of Human-Geosphere Intersections
}

\author{
Martin Bohle \\ Received: 12 November 2015; Accepted: 16 December 2015; Published: 6 January 2016 \\ Academic Editor: Jesus Martinez-Frias \\ Directorate-General for Research and Innovation, European Commission, Avenue du Loi 200, Brussels 1149, \\ Belgium; Martin.Bohle@ec.europa.eu; Tel.: +32-229-58111
}

\begin{abstract}
This essay introduces the notion of "human-geosphere intersections", describes "engineering" as an aspect of anthropogenic global change, and reflects on particular "paradigms" that may govern human-geosphere intersections. Seen conceptually, engineering is undertaken to meet needs and preferences of people within a composite framework of technological means, scientific insights, worldviews, and value system. Nowadays, the engineering of production systems, of consumption patterns, and of related intersections of human activities with the biotic and abiotic environments is a central feature of the anthropogenic global change process. In the last centuries, the cultural evolution of humankind took a development path that now is furthering an engineered planetary process to intersect properties of the geo-biosphere with the noosphere ("human-geosphere intersections"). Four paradigms, "adjustment", "dovetailing", "decoupling" and "modulating" are discussed, which may frame the engineering of human-geosphere intersections. These paradigms convene different insights into how bio-geosphere and noosphere function, how to alter human-geosphere intersections, and how engineering mediates between both spheres. Whatever paradigm is retained to engineer human-geosphere intersections, geoscience know-how has to be part of the noosphere, and geo-ethics should provide an orientation how human activities and geosphere should intersect.
\end{abstract}

Keywords: global environmental change; education and ethics; public engagement; social resilience

\section{Introduction}

During the last century the number of people on Earth, the patterns of their consumption of resources, and the engineering of their environments together accumulate in a process of anthropogenic global change [1]. Anthropogenic global change is a composite and historical process that is linking matters of social, cultural and political nature, thus how people interact with features of the planetary geo-biosphere [2-4]. The ensemble of actions and interactions of people is the noosphere of shared personal insights, which evolve over time. In addition, within the noosphere, it is conceived what economic activities shall be undertaken and how engineering shall be endeavored. Civil engineering is the human activity that relates human economic activities and the geosphere. Thus, it mediates between noosphere and geosphere [5] within the frame of evolving technologies and shared personal insights.

To simplify: humankind is an engineering species. Biological evolution of people came in pair with tool-making capacity. Prehistoric and historical evolution of humankind meant to modify environments to appropriate resources [6,7]. Throughout their cultural evolution, humans extended what they know how to engineer $[8,9]$. Nowadays, it is obvious that people are altering Earth [10]. Thus far, this kind of "terraforming" was a collateral of the human economic activities to appropriate resources or to shape the environment, which are undertaken to sustain a population of now several billion people. During the last decades, the side-effects of human economic activity, e.g., pollution at a planetary scale and anthropogenic global change, became so persistent that they had to be tackled. Re-engineering of production systems, consumption patterns and related intersections of human activities with the biotic 
and abiotic environment deemed to be a necessary endeavor; see Schwägerl [11] for an exhaustive review and detailed references. Four paradigms may frame this re-engineering effort with an overall purpose that is going beyond issues of scientific understanding and technical skills.

This essay outlines these paradigms and their context for acknowledging geosciences as part of people's daily life, i.e., making geosciences a part of the noosphere.

\section{Observations}

\subsection{Four Paradigms to Terraform Earth}

Regarding how production systems and consumption patterns are organized in the context of anthropogenic global change, the baseline paradigm is "adjustment" to the side-effects of "business as usual", i.e., to continue with the actual development paths of humankind. Three alternative paradigms are currently conceived. They are: (1) to alter human production/consumption patterns so that it dovetails into the bio/geosphere; (2) to segregate human production/consumption from bio/geosphere so that they are decoupled (eco-modernism); and (3) to modulate processes in the bio/geosphere (geo-engineering) so that they counteract the side-effects of human production/consumption patterns. Respectively, and to simplify for comparison, the notions "adjustment", "dovetailing", "decoupling" and "modulating" may qualify these four paradigms.

The current approach to how to handle anthropogenic global change applies the "dovetailing" paradigm. A key example is the Montreal Protocol for the abatement of ozone depleting substances. The "dovetailing" paradigm reflects experiences how to reduce human impact on the biosphere, e.g., impact of industrial pollution. The paradigm "to decouple" human activities from the environment (bio/geosphere) reflects the purpose of many engineering endeavors such as shore defenses and setting up an economy with circular matter fluxes. The paradigm of "modulating" geochemical and physical processes reflects the very purpose of human engineering, namely to keep the environment suitable for human appropriation.

As conventional as these four paradigms are, their conscious application on a planetary scale would be without precedence. Still, as ambitious as applying these paradigms "at planetary scale" is, they all fit well into the development path of (civil-)engineering endeavors of the last centuries. It is in this sense that people face a double habitual context when engineering at planetary scale. The available technological means, scientific understanding, and resources confine the engineering efforts. Within these limits, worldviews determine the choices. Thus, the ethical questions that engineering and geoscience imply in a professional context are put into a much more complex societal context, if undertaken at a planetary scale.

\subsection{Human-Geosphere Intersection}

\subsubsection{The Making of the Anthropocene}

Humankind's activity has left local traces in the geological record since the onset of agriculture in Neolithic ages [12]. The industrial revolution has printed a clear signal into the geological records at a planetary scale $[13,14]$. Since some decades ago, humankind's economic activity intersects the geosphere in a more general manner, either directly or mediated by the biosphere. The respective geological records at a planetary scale are forming [15].

It is the paradigm of present times that the production and consumption pattern of humankind causes fluxes of matter that modify Earth-system dynamics. This feature advocates renaming the present times Anthropocene, the time when humankind's activities modulate state and development path of planet Earth. Thus, and going beyond its scientific meaning, the notion Anthropocene conveys a double message $[1,16]$. First, that the development paths of humankind's history and natural earth-systems may intersect. Second, that to understand global processes, it may require synthesizing know-how of social sciences, humanities and natural sciences $[3,12,17,18]$. 
In such a synthesis, the natural sciences contribute to understanding the abiotic and biotic processes, which determine earth-systems dynamics. The social sciences and humanities contribute to understanding both, how people interact given their mental, subjective concepts (worldviews, culture, values, preferences, etc.), and how they collectively pursue their economic activities with the purpose to maintain their well-being, mutual care-taking, reproduction, and interaction. People's engineering endeavors provide the feedback between the noosphere of people's worldviews and preferences and the geosphere. Engineering works couple humankind's economic activities to the geosphere. The manner how these engineering works are conceived, designed, build and maintained depends on people's worldviews, culture, values, and preferences [19-21].

The interactions of people in the noosphere are of diverse nature and form, e.g., of technical, economic, social, cultural, artistic nature, and of public, collective or individual form. Furthermore, these people-people interactions are both; they are loaded, e.g., with worldviews and preferences, and they purposefully shape personal and shared views and coordinate actors. Thus, the making of the Anthropocene is as much a "mental" process in the noosphere [22], as it results from the "material" intersection of humankind's economic activities and the bio-geosphere [13,14]. In that context, engineering is the human activity that shapes the commons of the Anthropocene.

\subsubsection{Human-Geosphere Intersections and Engineering History}

Only recently human-geosphere intersections were studied as a particular historical process [9,14,23,24], showing how humankind appraised its actions including their intersect with the geo-biosphere. Generally, the intersection of people's activities and the geosphere was not a subject of a description of history, e.g., Fernández-Arnesto's [25] account of the last millennium. Nonetheless, reference was made to climate change and global impact of singular events such as the explosion of volcanoes like Santorini, Tambura or Krakatau. Only some scholars studied engineering history under a perspective that illustrates "human-geosphere intersection" although without naming it such, e.g., Viollet's [26] history of hydraulic works for irrigation systems, waterways, power systems or sanitary systems; notwithstanding, there is a comprehensive corpus of climate research about this specific human-geosphere intersection.

Simplified, the purpose of civil-engineering works is to build an intersection of humankind's economic activity and geosphere; e.g., managing rivers and their flood-planes [27]. Generalizing, engineering is about shaping environments for economic and societal purposes. Thus, history of engineering is about the paradigms that framed the intersections of activities of humans and abiotic, biotic and cultural environments; e.g., in Europe from the initial spread of agriculture, through medieval deforestation to contemporary urbanized societies.

During the last centuries, the scholarly study record shows both, the appraisal of engineering works [19] and concern of the state of flora and fauna [24,28] impacted by these works. The scholarly study record includes tales how to master hostile conditions, description of processes (in the noosphere) of how engineering skills developed, and accounts of deplorable intersections of human activities with the biosphere [29]. In comparison, natural science research of the historical development of the intersection of human activities with the geosphere is a quite recent study subject [30].

Following an extended period of admiration of engineering prowess and human interventions into biosphere and geosphere, today anthropogenic global change is part of a widespread perception of "an endangered state of the globe" [10,31]. That change of opinion began during the previous century with concerns about the state of the biosphere. It was perceived as endangered at the regional scale by industrial pollution, the inherent risk of chemical or nuclear technologies, or losses of species [32]. Similar concerns about the biosphere were also voiced in the 18th and 19th century at local scale when industrialization started [24]. Nowadays, people worry about the implications for their lifestyle and well-being, and also they wonder how "to better engineer" human interventions into biosphere and geosphere [5,33-35]. 


\subsubsection{Engineering Choices and Values}

To recall the obvious, when making choices, people are driven by both, their worldviews and preferences and their insights into societal, technical or natural processes. Within that context, the attitude of people towards risk, uncertainties, perception of facts and theories is very different. People's choices are subjective and vary with the context [36,37], e.g., whether the own person, the kin, or the own group is concerned, or whether an action is immediate, has happened, or will happen in the future. Going beyond concerns like "whether it is functioning", people intuitively tend to opt for what they consider as "right" or "worth" in the context of their individual worldview. When people are debating opportunities, change or risks then much of the debate is about "virtue" and what course of action is "worthwhile" $[7,38]$. That kind of debate also applies to engineering works, e.g., the construction of hydro-power plants [39]. Hydropower plants are an example of quite well-known engineering works that have huge impacts and benefits. Appraisal of these impacts and benefits are vigorously debated during planning, construction and operation drawing on different worldviews [40].

When considering engineering in a philosophical context, then engineering is the intended, value-driven change of environments with the purpose to facilitate production and reproduction. To that end, for example, engineering includes the building of infrastructures like shore defenses, which visibly interact with the geosphere. Likewise, engineering includes designing production systems, urban dwellings and consumption patterns that firmly but invisibly couple human activity with the geosphere through cycles of matter and energy. Last but not least, engineering is about how people govern the appropriation of living and non-living resources from the environment. Thus, intrinsically, engineering is about value systems, cultural choices and lifestyles.

The manner in how the debate on climate change is evolving shows that this debate is about worldviews [41]. Specialists, decision makers, and people ponder what hypotheses, theories or facts are. It is discussed how to handle uncertainty or hazards or whether to consider benefits for other people, in the past or for future generations [7,42]. Now that people have to handle anthropogenic global change, they have to choose how to re-engineer on a planetary scale the production systems, consumption patterns, and their natural, technical or cultural environments. Although such re-engineering would fit into the human culture, engineering global systems differs from previous engineering endeavors. The scale and complexity of the endeavor [43] is different, because anthropogenic global change-e.g., climate change-prescribes global commons for all people, whether the change is collateral or purposeful. Finally, engineering anthropogenic global change is loaded with implicit societal issues to an unprecedented level because of the impact on all people.

\subsection{Engineering Human-geoSphere Intersections}

Societies abundantly apply geoscience for their economic activities. Understanding the features of rock, soil, water and air is essential for the production of many goods. Craftsmen, technicians, architects, and engineers apply geoscience know-how when engineering environments or creating artifacts, e.g., extraction of minerals, laying foundations for buildings, or managing floodplains. Geoscience know-how makes the engineering works (transport systems, energy systems, dwellings, agriculture, waste treatment, etc.) dovetailing economic activities and geosphere. Likewise, maintaining living conditions and individual well-being requires geoscience know-how. Prominent examples are ventilation, evacuation of excess water, controlling pollution from combustion engines, or maintaining radio connections when solar storms hit the Earth. Many people may not recognize how geoscience know-how mediate the interaction of human activities and processes in the geosphere because that know-how is part of habitual experiences, common sense, general education or specific vocational training. Notwithstanding any lack of conscious insights, as discussed above, the noosphere of the people-people interactions of contemporary societies and the geosphere are well coupled.

Considering anthropogenic global change, several "engineering paradigms" can be distinguished, and will be sketched out below. Each reflects how worldviews and preferences determine the choices 
how to undertake engineering works. As introduced above, the habitual approach of the last centuries may be qualified by the notion "adjustment" (to collateral damage). The notions "dovetailing", "decoupling" and "modulating" may label alternative engineering paradigms and are used for the purpose of this essay (instead of the habitual terms "adaptation", "mitigation", "eco-modernism" and "geo-engineering").

\subsubsection{Paradigm: "Adjustment"}

Since some decades ago, people's engineering works increased matter and energy fluxes across the interfaces that couple human activities and Earth's natural systems. The stratospheric ozone depletion was an early experience that triggered intergovernmental cooperation. Leakage and waste of industrial chemicals had reached a scale that their derivatives could accumulate in the stratosphere and modify chemical processes on a planetary scale. The accumulation of ozone depleting substances was sufficient to damage the ozone layer in the stratosphere. A more recent sign of anthropogenic global change is the rising atmospheric carbon dioxide concentrations, which is now the most prominent example of modified global geochemical cycles. These incremental modifications accumulated to a new feature of humankind contemporary engineering, namely anthropogenic global change.

These impacts of the humankind's economic activity on the geosphere were unintended. A kind of "terraforming by numbers" happened as a collateral effect of populations increase; political, social and individual choices regarding appropriation of resources; and engineering the environment to meet needs and preference of several billion people. The implicit engineering paradigm that a "business as usual scenario" applies may be labeled "adjustment". Thus, each new engineering work is designed to fit the local status quo and forecast of changes; e.g., shore defenses are scaled up to match the expected sea-level rise.

\subsubsection{Paradigm: "Dovetailing”}

This engineering paradigm is about the incremental adjustment of human production systems and consumption patterns. It aims to dovetail anthropogenic and natural fluxes of matter to mitigate humankind's impact on Earth systems dynamics. Today, this kind of engineering is a confirmed feature of public regulated production systems and consumption patterns. Debates are about the pace and degree of the incremental adjustment ("greening") that is appropriate [44,45]. Thus, the debate is about whether measures are sufficient to have an effect and are not too costly regarding new investments and depreciation of sunken investments; the recent meeting (Conference of the Parties) in Paris (December 2015) delivering a most prominent example when discussing climate change and agreeing on the successor for the Kyoto Protocol.

Early historical forerunners of this "dovetailing" paradigm can be found in the energy-limited economies of societies before the industrial revolution [24,46], which focused on resource efficiency. The appeal of this engineering paradigm, which supports sustainability [29] is double for contemporary societies. First, it incrementally modifies the traditional development paths of our societies. Second, it can generalize practices, including a political process to find consensus, which previously have applied successfully to tackle regional or local pollution, e.g., banning of ozone-depleting substances or reducing acid rain by capping sulfate emissions.

\subsubsection{Paradigm: "Decoupling"}

This engineering paradigm, self-labeled as "ecomodernism" [47], is a recent branch of thought within the paradigms of "better engineering the Anthropocene". This paradigm is about decoupling anthropogenic and natural fluxes of matter to reduce human impact on earth systems. The decoupling shall be driven by enhancing non-fossil, mainly nuclear power production (the likelihood the renewable technologies will provide sufficient power is questioned) up to a level that matter is kept cycling predominately within the human economy. An economy of a stable human population of 
mainly urban lifestyle is envisaged that is decoupled from the geosphere and biosphere, at least to an advanced degree.

The concepts used to describe "ecomodernism" aligns with the initial paradigm of Western, industrialized societies, namely to gain independence from natural processes. It suggests boosting the development path of the last centuries. This paradigm is appealing because it is preserving the value of past investments. Whether the experiences to decouple anthropogenic fluxes of matter from natural fluxes are sufficient to further the initial paradigm of industrialization is debated. The central assumptions are massive use of nuclear power and the forecast that population growth and per capita consumption will peak mid-century.

\subsubsection{Paradigm: "Modification"}

This engineering paradigm is about the adjustment of natural processes to counteract anthropogenic global change. Therefore, it is labeled "geo-engineering". It is intended to modify earth's physical and bio-geological systems in a manner that they can handle the anthropogenic fluxes of matter and energy. That kind of thinking applies a traditional human paradigm namely to purposefully adjust environments to people's preferred ways of being instead to modify production systems and consumption patterns. Such an approach has the advantage of preserving the value of past investments. Currently, technical options for geo-engineering are researched, risks are analyzed, and political processes for adoption of geo-engineering measures are discussed [33,48-50].

\subsubsection{Commonalities of Engineering Paradigms}

These four paradigms exhibit a common cultural trait of societies that face problems, namely to tackle them through "better engineering". The engineering shall alter the coupled Earth system of geosphere and noosphere, although from different perspectives that are depending on the respective paradigm. These paradigms have a set of ethical dilemmas in common.

First, it is intended to engineer systems that have non-linear dynamics with feedback. Such systems exhibit chaotic dynamics that show a behavior that is difficult to forecast. This feature renders design, implementation, and operation of engineering works challenging. Therefore, non-intended and counter-intuitive system behavior is likely.

Second, in the past when engineering could not tackle a problem successfully, emigration was an option. Evidently, leaving Earth is not an option. However, "internal migration" to avoid the regional impact of the anthropogenic global change is an option that is already depicted by some as an emerging feature. That dimension of "non-escape" sharpens the ethical issues of engineered anthropogenic change.

Third, the studies of technical options for geo-engineering (paradigm: "modification") reflect on consensus building as a necessary element to take action. Obviously, this insight should apply to any engineering paradigm to handle anthropogenic global change. Consensus building is also inherent in the paradigm of "dove-tailing" but seems to be less inherent to engineering cultures that accept "collateral effects" or aims at "decoupling". For the former, a requirement for financial compensation for collateral damage may be a driver to find some consensus.

Fourth, application of these paradigms needs that people gain insights into the intersection of human activity and geosphere. To make the altered intersections work, these insights should be at the center of people's lifestyles. The degree of understanding "how to build a habitable planet" [51] may vary depending on the paradigm. On first sight, to modulate or to dovetail seems to be a more ambitious approach than accepting collateral effects. Likewise, decoupling seems to be simpler regarding the level of understanding that may be needed. Notwithstanding the different degree of people's insight, finally these differences may be of lesser importance than to acknowledge both, the existence of human-geosphere intersections and the endeavor that their conscious alteration through engineering at planetary scale implies. 


\subsection{Ethics and Human-geosphere Intersections}

Our species has acquired the power to engineer planet Earth. However, many people may not take notice of the processes and phenomena that characterize the intersections of human activity and geosphere. As discussed above, anthropogenic global change is about engineering the intersections of human economic activities and the geosphere in function of people's worldviews and preferences. Although so far anthropogenic global change was unintended, the ongoing anthropogenic global change is engineered consciously. As any engineering work, therefore, anthropogenic global change is subject to the human value-systems [21], which underpin people's worldviews and preferences. However, people can tackle anthropogenic global change as part of their worldviews and preferences only if insights into human-geosphere intersections become integrated into their interactions in the noosphere. This integration is needed because people's lifestyle and living conditions will alter when human-geosphere intersections change. People will judge the alterations by their preferences, values, and worldviews; and then will decide and react accordingly. To that end, the practitioners, professionals, and researchers who understand how intersections of human activity and geosphere function, have to share their insights. The sharing has to be with decision makers and layperson and has to include value statements, and thus is done in the context of worldviews and preferences. To that end, paradigms are helpful to conceptualize an understanding of functions and worldviews.

Sharing of understanding about anthropogenic global change is a demanding process that has to handle multifaceted content. Handling the problem of stratospheric ozone depletion has taught this. Effect of increased UV-radiation because of a depleted ozone layer in the stratosphere are quite easy to conceptualize, as they were ranging from increased mutation rates to abandoning sunbathing on Australian beaches [52]. As experience with climate change showed, the cause-effect relations of the human-geosphere intersections are difficult to determine, even in hindsight. The processes at intersections often are non-linear and networked. Therefore, their dynamics are complex, possibly chaotic and forecasting them will be challenging [53-55]. Notwithstanding this difficulty, when human-geosphere intersections get engineered then some forecasting skills will be needed.

As described above, four distinct engineering paradigms ("adjustment" "dovetailing", "decoupling" and "geo-engineering") are conceptualized as options to alter the human-geosphere intersections. Application of any of these paradigms, or of a mix of them, will raise ethical dilemmas and non-intended side-effects [56]. Among these ethical dilemmas will be conflicting values, uneven distribution of risks, impacts, losses, and benefits, or collateral impacts like exposure to unexpected side-effects. The side-effects may range from challenging individual lifestyles to compromising basic needs. It can be expected that debates will be vigorous, e.g., whether a side-effect was to be expected or was intentional. Generalizing, if altering of human-geosphere intersections gets addressed as engineering works, then the ethics of risk-taking, managing uncertainties or revising options will be needed in a context of applied geoscience. Thus, practitioners of geo-ethics [57] should be ready to provide answers on how to take these matters up.

\section{Discussion}

Modern societies highly value their capability to engineer, e.g., their internal processes, environments and the interactions between society and environment. Engineering works are undertaken to meet needs and preferences of people within a framework of technological means, scientific insights, worldviews and related value-systems.

Overall, "engineering" had been quite a successful approach of the human species, if measured by the (historically recent) exponential growth of the number of people. Recently, the engineering power of people started to influence planetary fluxes of matter and energy, e.g., people are initiating the Anthropocene. Until now, people did not intend to modify planetary fluxes of matter and energy or to engineer them. Although people were aware of the effect of their cumulative activities on the biosphere, so far they ignored the intersection of human economic activity with the geosphere. The phase of 
history during which anthropogenic global change happened unnoticed has ended. Having lost innocence, nowadays anthropogenic global change is an intentional act [23].

Beyond continuing the current development path to alter Earth, alternatives exist on how to handle human-geosphere intersections. Each alternative has its intrinsic scientific, technical and ethical particularities, which outline a specific "engineering culture", which require study in its own. To compare these alternatives, at a very aggregated level, the baseline is "business as usual": the cumulative effect of human economic activity on the geosphere is accepted, monitored and factored into a next generation of engineering works. Continuing such a process "terraforming by number" may be an option because it deemed impossible to modify the current societal development paths.

Instead of a "business as usual" scenario, the incremental adjustment of the current development paths of production systems and consumption patterns is the actual political approach. To that end, anthropogenic and natural fluxes of matter and energy are "dovetailed" by "greening" the production systems and consumption patterns. An alternative ("eco-modernism"), which currently is a concept, emphasizes strengthening some of the traditional development paths of industrialized societies. The target is to "decouple" anthropogenic and natural fluxes of matter and energy. A further alternative ("geo-engineering"), which is currently researched, intends to "modulate" natural fluxes of matters to counter the effect of anthropogenic fluxes of matter, yet keeping societal development paths unchanged.

Whatever a particular engineering decision, "how to modify intersections of humankind's activities and the geosphere" will be given the available options, it will depend much on people's preferences and worldviews. Conscientiously, protagonists of any alternative argue why choices are engineering-wise "sound", economically "cost-effective" and ethically "right". Prominent examples are the "Eomodernist Manifesto", by that Asafu-Adjay and coauthors [47] are advocating "decoupling"; Schwägerl's [11] advocacy for "dovetailing"; or Rayner and coauthors [58] presentation of "Oxford Principles" in support of "modulating" planetary systems.

Current public policies apply a mix of "adjustment" and "dovetailing" paradigms when regulating production systems and consumption patterns. The intergovernmental negotiations on global climate change show how value-loaded are interventions into human-geosphere intersections. The range of scientific, technical and economic matters include their specific ethical issues, namely whether scientific and engineering choices are professionally "sound". Likewise, the overarching societal matters are value-loaded, e.g., how to appropriate and distribute natural resources for what cost, accepted side-effects, and with what risk of further collateral effects. Even if these ethical issues seem familiar regarding their general nature [8], their complexity has no precedence, simply because of the number of people who will be subject to consequences of the choices made, and the range of worldviews and preferences that these people have.

For any "engineering culture", the particular ethical issues of "engineering Planet Earth" require that people have insights into the functioning of the human-geosphere intersections [59]. To render choices or decisions operable, people have to accept them. For decisions to be accepted requires that the dynamics of the people-people interactions in noosphere are understood so that they can be factored into the decision process. Thus, for "engineering planet Earth" [60], reliable insights provided by humanities and social sciences are needed, which have to enlarge [61] sound scientific, engineering and economic knowledge that was accumulated during the last decades [62].

\section{Conclusions}

In the context of the ongoing anthropogenic global change process, humankind's engineering works have a particular function, they are the means to intersect geosphere and noosphere. Engineering is understood to be the intended, value-driven change of environments with the purpose of facilitating production and reproduction. Implications of four paradigms are discussed, which each may frame in a particular manner, the engineering of human-geosphere intersections in the context of anthropogenic global change. The results are that whatever paradigm or mix of paradigms 
a stakeholder may favor: geoscience know-how is paramount for the engineering works that are undertaken and framed by these "engineering paradigms". Therefore, to make choices, geoscience know-how has to become an essential component of the noosphere in the same manner as technological know-how became an intrinsic part of the noosphere during the last century. Public debates on "how to engineering human-geosphere intersections" will have to apply geoscience expertise. In these application contexts, ethics will be essential as a means to deal with the way of human thinking and acting and to guide appropriate behaviors and practices where human activities intersect the geosphere.

For the Anthropocene, the recognition of geoscience know-how as part of the noosphere seems obvious and it should possibly be twinned with geo-ethics as an orientation of how human activities and geosphere should intersect. In that sense, this discussion offers options for further studies (e.g., the economics of engineering global change, public awareness of human-geosphere intersections, geographical dispersion of people, resources or risks, etc.) that relate to engineering, geosphere, and noosphere.

Acknowledgments: I am grateful that my employer granted the opportunity to pursue scientific activities along with my professional duties. The opinions expressed in this essay are mine, the author and not of my employer.

Conflicts of Interest: The author declares no conflict of interest.

\section{References}

1. Monastersky, R. The Human Age. Nature 2015, 519, 144-147. [CrossRef] [PubMed]

2. Lewis, S.L.; Maslin, M.A. Defining the Anthropocene. Nature 2015, 519, 171-180. [CrossRef] [PubMed]

3. Braje, T.J.; Erlandson, J.M. Looking forward, looking back: Humans, anthropogenic change, and the Anthropocene. Anthropocene 2013, 4, 116-121. [CrossRef]

4. Folke, C.; Jansson, Å.; Rockström, J.; Olsson, P.; Carpenter, S.R.; Stuart Chapin, F.; Crépin, A.S.; Daily, G.; Danell, K.; Ebbesson, J.; et al. Reconnecting to the biosphere. Ambio 2011, 40, 719-738. [CrossRef] [PubMed]

5. Bracmort, K.; Lattanzio, R.K. Geoengineering: Governance and Technological Policy. Available online: https:/ / books.google.com/books?hl=en\&lr=\&id=oAI4ojo7uNAC\&oi=fnd\&pg=PA1\&dq=Geoengineering:+ Governance+and+Technological+Policy\&ots=yj3hXmgKCT\&sig=7UVdHFnwftfEK1agl8V-uYzNYZ0\#v= onepage\&q=Geoengineering $\% 3 \mathrm{~A} \% 20$ Governance $\% 20$ and $\% 20$ Technological $\% 20$ Policy $\& \mathrm{f}=$ false $($ accessed on 12 November 2015).

6. Smith, B.D.; Zeder, M.A. The onset of the Anthropocene. Anthropocene 2013, 4, 8-13. [CrossRef]

7. Tickell, C. Societal responses to the Anthropocene. Philos. Trans. A Math. Phys. Eng. Sci. 2011, 369, $926-932$. [CrossRef] [PubMed]

8. Bugliarello, G. Ideal of civil engineering. J. Prof. Issues Eng. Educ. Pract. 1994, 120, 290-294. [CrossRef]

9. Bonneuil, C.; Fressoz, J.-B. L'événement Anthropocène—La Terre, L'histoire et Nous; Seuil: Paris, France, 2013.

10. Barnosky, A.D.; Hadly, E.A; Bascompte, J.; Berlow, E.L.; Brown, J.H.; Fortelius, M.; Getz, W.M.; Harte, J.; Hastings, A.; Marquet, P.A.; et al. Approaching a state shift in Earth's biosphere. Nature 2012, 486, 52-58. [CrossRef] [PubMed]

11. Schwägerl, C. The Anthropocene-The Human Era and How It Shapes Our Planet; Synergetic Press: Santa Fe, NM, USA, 2014.

12. Foley, S.F.; Gronenborn, D.; Andreae, M.O.; Kadereit, J.W.; Esper, J.; Scholz, D.; Pöschl, U.; Jacob, D.E.; Schöne, B.R.; Schreg, R.; et al. The Palaeoanthropocene-The beginnings of anthropogenic environmental change. Anthropocene 2013, 3, 83-88. [CrossRef]

13. Ellis, E.C.; Goldewijk, K.K.; Siebert, S.; Lightman, D.; Ramankutty, N. Anthropogenic transformation of the biomes, 1700 to 2000. Glob. Ecol. Biogeogr. 2010, 19, 589-606. [CrossRef]

14. Ellis, E.C. Anthropogenic transformation of the terrestrial biosphere. Philos. Trans. A Math. Phys. Eng. Sci. 2011, 369, 1010-1035. [CrossRef] [PubMed]

15. Zalasiewicz, J.; Waters, C.N.; Williams, M.; Barnosky, A.D.; Cearreta, A.; Crutzen, P.; Ellis, E.; Ellis, M.A.; Fairchild, I.J.; Grinevald, J.; et al. When did the Anthropocene begin? A mid-twentieth century boundary level is stratigraphically optimal. Quat. Int. 2015. [CrossRef] 
16. Bohle, M. Recording the onset of the Anthropocene. In Engineering Geology for Society and Territory; Lollino, G., Arattano, M., Giardino, M., Oliveira, R., Peppoloni, S., Eds.; Springer: Berlin, Germany, 2014; Volume 7, pp. 161-163.

17. Weisz, H.; Clark, E. Society-nature coevolution: Interdisciplinary concept for sustainability. Geogr. Ann. Ser. B Hum. Geogr. 2011, 93, 281-287. [CrossRef]

18. Bergthaller, H.; Emmett, R.; Johns-Putra, A.; Kneitz, A.; Lidström, S.; McCorristine, S.; Pérez Ramos, I.; Phillips, D.; Rigby, K.; Robin, L. Mapping Common Ground: Ecocriticism, Environmental History, and the Environmental Humanities. Environ. Humanit. 2014, 5, 261-276.

19. Landes, D.S. The Unbound Prometheus; Cambridge University Press: Cambridge, UK, 2003.

20. Malanima, P. Europäische Wirtschaftsgeschichte 10-19. Jahrhundert; Böhlau UTB: Stuttgart, Germany, 2010.

21. Palsson, G.; Szerszynski, B.; Sörlin, S.; Marks, J.; Avril, B.; Crumley, C.; Hackmann, H.; Holm, P.; Ingram, J.; Kirman, A.; et al. Reconceptualizing the "Anthropos" in the Anthropocene: Integrating the Social Sciences and Humanities in Global Environmental Change Research. Environ. Sci. Policy 2012. [CrossRef]

22. Biermann, F.; Betsill, M.M.; Vieira, S.C.; Gupta, J.; Kanie, N.; Liverman, D.; Schroeder, H.; Lebel, L.; Siebenhüner, B.; Yanda, P.Z.; et al. Navigating the Anthropocene: The Earth System Governance Project strategy paper. Curr. Opin. Environ. Sustain. 2010, 2, 202-208. [CrossRef]

23. Ellis, M.A.; Trachtenberg, Z. Which Anthropocene is it to be? Beyond geology to a moral and public discourse. Earth Future 2014. [CrossRef]

24. Fressoz, J.-B. L'Apocalypse Joyeuse-Une Histoire du Risque Technologique; Seuil: Paris, France, 2012.

25. Fernandez-Armesto, F. Millenium: A History of the Last Thousand Years; Charles Scribner's Sons: New York, NY, USA, 1996.

26. Viollet, P. L'Hydraulique Dans Les Civilisations Anciennes: 5000ans D'Histoire; Presses des Ponts: Toulon, France, 2000.

27. Syvitski, J.P.M.; Kettner, A. Sediment flux and the Anthropocene. Philos. Trans. R. Soc. A Math. Phys. Eng. Sci. 2011, 369, 957-975. [CrossRef] [PubMed]

28. Lynn, W.S. Animals, Ethics and Geography. In Animal Geographics: Plan, Politics and Identity in the Nature Cultural Borderlands; Verso: London, UK, 1998; pp. 280-298.

29. Diamond, J. Collapse: How Societies Choose to Fail or Succeed; Viking Penguin, 2005.

30. Sirocko, F. Wetter, Klima, Menschheitentwicklung: Von der Eiszeit bis ins 21.Jahrhundert; Konrad Theiss: Stuttgart, Germany, 2012.

31. Steffen, W.; Sanderson, R.A.; Tyson, P.D.; Jäger, J.; Matson, P.A.; Moore, B., III; Oldfield, F.; Richardson, K.; Schellnhuber, H.J.; Turner, B.L.; et al. Global Change and the Earth System: A Planet under Pressure; Springer: Berlin, Germany, 2005.

32. Cardinale, B.; Duffy, J.; Gonzalez, A. Biodiversity loss and its impact on humanity. Nature 2012, 486, 59-67. [CrossRef] [PubMed]

33. Barrett, S. The incredible economics of geoengineering. Environ. Resour. Econ. 2008, 39, 45-54. [CrossRef]

34. Ryghaug, M.; Holtan Sorensen, K.; Naess, R. Making sense of global warming: Norwegians appropriating knowledge of anthropogenic climate change. Public Underst. Sci. 2011, 20, 778-795. [CrossRef] [PubMed]

35. Sadler-Smith, E. Making sense of global warming: Designing a human resource development response. J. Eur. Train. Ind. 2014, 38, 387-397.

36. Gibson-Graham, J.K.; Roelvink, G. An Economic Ethics for the Anthropocene. Antipode 2010, 41, $320-346$. [CrossRef]

37. Sutherland, W.J.; Bellingan, L.; Bellingham, J.R.; Blackstock, J.J.; Bloomfield, R.M.; Bravo, M.; Cadman, V.M.; Cleevely, D.D.; Clements, A.; Cohen, A.S.; et al. A collaboratively-derived science-policy research agenda. PLoS ONE 2012, 7, 3-7. [CrossRef] [PubMed]

38. Ehrlich, P.R.; Kareiva, P.M.; Daily, G.C. Securing natural capital and expanding equity to rescale civilization. Nature 2012, 486, 68-73. [CrossRef] [PubMed]

39. Sternberg, R. Hydropower: Dimensions of social and environmental coexistence. Renew. Sustain. Energy Rev. 2008, 12, 1588-1621. [CrossRef]

40. Fu, B.; Wang, Y.K.; Xu, P.; Yan, K.; Li, M. Value of ecosystem hydropower service and its impact on the payment for ecosystem services. Sci. Total Environ. 2014, 472, 338-346. [CrossRef] [PubMed] 
41. Krauss, W. Anthropology in the Anthropocene: Sustainable development, climate change and interdisciplinary research. In Grounding Global Climate Change. Contributions from the Social and Cultural Sciences; Springer: Berlin, Germany, 2015; pp. 59-76.

42. Aufenvenne, P.; Egner, H.; von Elverfeldt, K. On Climate Change Research, the Crisis of Science and Second-order Science. Constr. Found. 2014, 10, 120-129.

43. Bodansky, D. The who, what, and wherefore of geoengineering governance. Clim. Chang. 2013, 121, 539-551. [CrossRef]

44. Godin-Beekmann, S. The stratospheric ozone layer and the Montreal Protocol. La Meteorol. 2013, 8, 59-66.

45. Jacobs, J.R. The precautionary principle as a provisional instrument in environmental policy: The Montreal Protocol case study. Environ. Sci. Policy 2014, 37, 161-171. [CrossRef]

46. Brown, A. Just Enough: Lessons in Living Green from Traditional Japan; Tuttle Publishing: North Clarendon, VT, USA, 2012.

47. Asafu-Adjaye, J.; Blomquist, L.; Brand, S.; Brook, B.; DeFries, R.; Ellis, E.; Foremann, C.; Keith, D.; Lewis, M.; Lynas, M.; et al. An Ecomodernist Manifesto. Available online: http://www.ecomodernism.org (accessed on 10 November 2015).

48. Victor, D.G. On the regulation of geoengineering. Oxf. Rev. Econ. Policy 2008, 24, 322-336. [CrossRef]

49. Corner, A.J.; Pidgeon, N.F. Geoengineering the Climate: The Social and Ethical Implications: EBSCOhost. Environ. Sci. Policy Sustain. Dev. 2010, 52, 24-37. [CrossRef]

50. Gardiner, S.M. The Desperation Argument for Geoengineering. Polit. Sci. Polit. 2013, 46, 28-33. [CrossRef]

51. Langmuir, C.; Broecker, W. How to Build a Habitable Planet; Princton University Press: Princton, NJ, USA, 2012.

52. Newman, P.A.; McKenzie, R. UV impacts avoided by the Montreal Protocol. Photochem. Photobiol. Sci. 2011, 10, 1152-1160. [CrossRef] [PubMed]

53. Allenby, B.R.; Sarewitz, D. The accelerating techno-human future. Futurist 2011, 45, 30-33.

54. Allenby, B.R.; Sarewitz, D. The Techno-Human Condition; MIT Press: Cambridge, MA, USA, 2011.

55. Banerjee, B. The limitations of geoengineering governance in a world of uncertainty. Stanf. J. Law Sci. Policy 2011, 240, 15-36.

56. Anshelm, J.; Hansson, A. Battling Promethean dreams and Trojan horses: Revealing the critical discourses of geoengineering. Energy Res. Soc. Sci. 2014, 2, 135-144. [CrossRef]

57. Peppoloni, S.; Di Capua, G. Geoethics: The Role and Responsibility of Geoscientists; The Geological Society: London, UK, 2015.

58. Rayner, S.; Heyward, C.; Kruger, T.; Pidgeon, N.; Redgwell, C.; Savulescu, J. The Oxford Principles. Clim. Change 2013, 121, 499-512. [CrossRef]

59. Fox, T.A.; Chapman, L. Engineering geo-engineering. Meteorol. Appl. 2011, 18, 1-8. [CrossRef]

60. Glaser, J.A. Geoengineering the climate. Design 2009, 12, 91-95. [CrossRef]

61. Wilson, E.O. The Meaning of Human Existence; W.W. Norton \& Company: New York, NY, USA, 2014.

62. Morton, O. The Planet Remade: How Geoengineering Could Change the World; Princeton University Press: Princeton, NJ, USA, 2012.

(C) 2016 by the author; licensee MDPI, Basel, Switzerland. This article is an open access article distributed under the terms and conditions of the Creative Commons by Attribution (CC-BY) license (http://creativecommons.org/licenses/by/4.0/). 